\title{
New $\beta$-galactosidase producers with potential for prebiotic synthesis
}

\author{
Sara C. Silvério ${ }^{\mathrm{a}, *}$, Eugénia A. Macedo ${ }^{\mathrm{b}}$, José A. Teixeira ${ }^{\mathrm{a}}$, Lígia R. Rodrigues ${ }^{\mathrm{a}}$ \\ a CEB-Centre of Biological Engineering, Universidade do Minho, Campus de Gualtar, 4710-057 Braga, Portugal \\ ${ }^{\mathrm{b}}$ Laboratory of Separation and Reaction Engineering - Laboratory of Catalysis and Materials (LSRE-LCM), Faculty of Engineering, University of Porto, Rua Dr. Roberto \\ Frias, 4200-465 Porto, Portugal
}

\section{G R A P H I C A L A B S T R A C T}

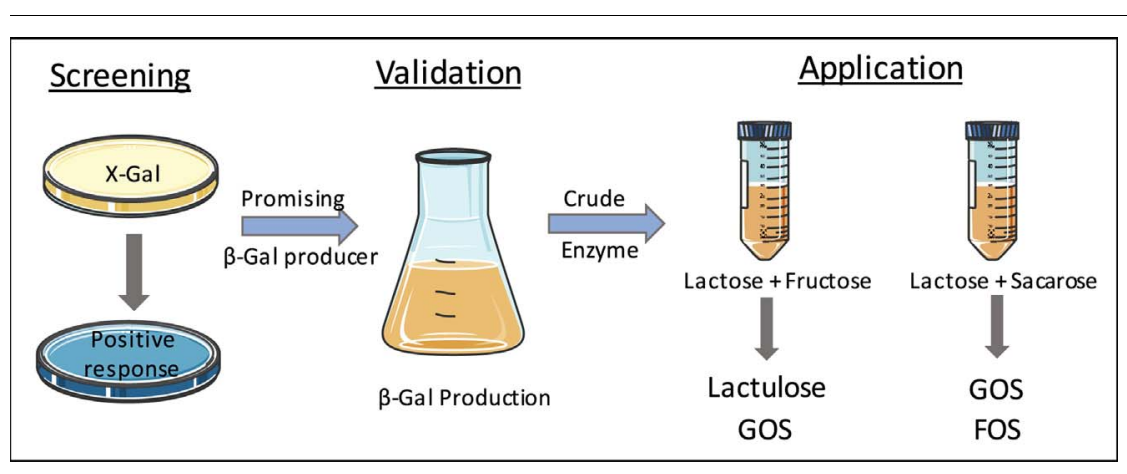

\section{A R T I C L E I N F O}

\section{Keywords:}

$\beta$-Galactosidase

Fungal strains

Lactulose

Galacto-oligosaccharides

Fructo-oligosaccharides

\begin{abstract}
A B S T R A C T
$\beta$-Galactosidases (EC 3.2.1.23) are interesting enzymes with potential application in the pharmaceutical and food industry. In this work, a screening study was carried out to identify new fungal sources of $\beta$-galactosidase. A total of 50 fungi were evaluated using a chromogenic test performed in agar plates. The most promising microorganisms were validated as effective $\beta$-galactosidase producers under submerged fermentation conditions. The crude $\beta$-galactosidases were characterized regarding their optimal $\mathrm{pH}(3.0-5.5)$ and temperature $\left(45-65^{\circ} \mathrm{C}\right)$. All enzymes showed ability to synthesize lactose-based prebiotics, namely lactulose (maximal yield 3.3\%) and a galacto-oligosaccharide (GOS) (maximal yield 20\%). Additionally, some enzymatic extracts with fructosyltransferase activity allowed to produce other type of prebiotics, namely fructo-oligosaccharides (FOS). This work, reports for the first time the simultaneous synthesis of different mixtures of GOS (2-15\% yield and $0.07-0.5 \mathrm{~g} / \mathrm{L} \cdot \mathrm{h}^{-1}$ productivity) and FOS (4-30\% yield and $0.1-1 \mathrm{~g} / \mathrm{L} \cdot \mathrm{h}^{-1}$ productivity) by crude extracts exhibiting dual enzymatic activity.
\end{abstract}

\section{Introduction}

$\beta$-Galactosidases (EC 3.2.1.23), frequently known as lactases, are widely used in lactose hydrolysis. This disaccharide is present in mammalian milk in concentrations up to $10 \%(\mathrm{w} / \mathrm{w})$, depending on the species (Fox and McSweeney, 1998). The sweetness of lactose corresponds to approximately $20 \%$ of that of sucrose and its aqueous solubility is low compared with other sugars (Gänzle et al., 2008). Additionally, lactose is a hygroscopic sugar which frequently suffers undesirable crystallization. The hydrolytic activity of $\beta$-galactosidase is

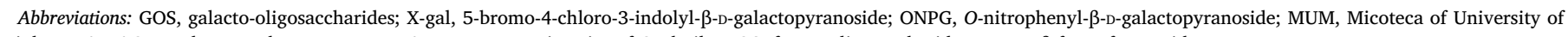
Minho; DIA-UAC, Food Research Department - Autonomous University of Coahuila; FOS, fructo-oligosaccharides; FFase, $\beta$-fructofuranosidase

* Corresponding author.

E-mail address: sarasilverio@deb.uminho.pt (S.C. Silvério). 
Table 1

Results obtained for the 50 fungi in the chromogenic test with X-gal.

\begin{tabular}{|c|c|c|c|c|c|c|c|c|}
\hline \multicolumn{3}{|l|}{ Group 1} & \multicolumn{3}{|l|}{ Group 2} & \multicolumn{3}{|l|}{ Group 3} \\
\hline Fungi & Code & Level $^{\mathrm{a}}$ & Fungi & Code & Level $^{\mathrm{a}}$ & Fungi & Code & Level $^{\mathrm{a}}$ \\
\hline Aspergillus aculeatus & MUM 03.11 & 1 & Penicillium aurantiogriseum & MUM 03.21 & 2 & Alternaria sp. & MUM 00.23 & 0 \\
\hline Aspergillus bertholletiae & MUM 12.11 & 0 & Penicillium brevicompactum & MUM 02.07 & 3 & Beauveria bassiana & MUM 02.39 & 2 \\
\hline Aspergillus brasiliensis & MUM 06.179 & 2 & Penicillium cammemberti & MUM 9210 & 1 & Botrytis cinerea & MUM 10.142 & 2 \\
\hline Aspergillus carbonarius & 01UAs130 & 3 & Penicillium chrysogenum & MUM 03.18 & 2 & Byssochlamys fulva & MUM 9827 & 3 \\
\hline Aspergillus chevalieri & MUM 00.07 & 2 & Penicillium digitatum & MUM 9811 & 1 & Cladosporium cladosporioides & MUM 9706 & 2 \\
\hline Aspergillus flavus & MUM 00.06 & 1 & Penicillium expansum & MUM 02.14 & 1 & Curvularia clavata & MUM 9724 & 1 \\
\hline Aspergillus foetidus & 01UAs162 & 2 & Penicillium italicum & MUM 02.25 & 3 & Fusarium culmorum & MUM 9701 & 0 \\
\hline Aspergillus fumigatus & MUM 9802 & 2 & Penicillium paxilli & MUM 07.03 & 0 & Fusarium solani & MUM 9205 & 1 \\
\hline Aspergillus ibericus & MUM 03.49 & 3 & Penicillium purpurogenum & DIA-UAC GH2 & 3 & Mucor sp. & DIA-UAC 3P & 3 \\
\hline Aspergillus lacticoffeatus & MUM 06.150 & 2 & Penicillium roqueforti & MUM 9838 & 1 & Myceliophthora lutea & MUM 9815 & 2 \\
\hline Aspergillus minisclerotigenes & MUM 10.229 & 1 & Penicillium spinulosum & MUM 02.34 & 3 & Neurospora crassa & MUM 11.01 & 3 \\
\hline Aspergillus niger & 01 UAs83 & 3 & Penicillium verrucosum & MUM 9745 & 2 & Paecilomyces variotii & MUM 9737 & 3 \\
\hline Aspergillus ochraceus & MUM 9302 & 0 & & & & Phoma violacea & MUM 9708 & 1 \\
\hline Aspergillus restrictus & MUM 9824 & 3 & & & & Trametes versicolor & MUM 04.100 & 2 \\
\hline Aspergillus sergii & MUM 10.208 & 0 & & & & & & \\
\hline Aspergillus sp. & MUM 10.249 & 1 & & & & & & \\
\hline Aspergillus sydowii & MUM 07.14 & 1 & & & & & & \\
\hline Aspergillus tamarii & MUM 00.10 & 0 & & & & & & \\
\hline Aspergillus transmontanensis & MUM 10.211 & 2 & & & & & & \\
\hline Aspergillus tubingensis & MUM 06.152 & 2 & & & & & & \\
\hline Aspergillus ustus & MUM 00.12 & 1 & & & & & & \\
\hline Aspergillus uvarum & MUM 08.01 & 2 & & & & & & \\
\hline Aspergillus versicolor & MUM 00.20 & 0 & & & & & & \\
\hline Aspergillus violaceofuscus & MUM 03.02 & 2 & & & & & & \\
\hline
\end{tabular}

a Level of response: (0) no blue color; (1) slight blue color; (2) blue color; and (3) deep blue color.

commonly applied in the food industries aiming to reduce the lactose content of dairy products, preventing lactose crystallization problems and increasing sweetness, flavor and solubility (Gänzle et al., 2008). Furthermore, the hydrolysis of lactose into D-glucose and D-galactose allows the production of lactose-free products suitable for lactose-intolerant people. A significant percentage of the global adult population is affected by lactose intolerance due to $\beta$-galactosidase deficiency. This deficiency results in malabsorption of lactose which can cause several undesirable symptoms such as abdominal cramps, bloating, diarrhea or flatulence (Bhatnagar, 2007).

Some $\beta$-galactosidases can also catalyze transgalactosylation reactions and have been successfully applied in the synthesis of lactosebased prebiotics, such as galacto-oligosaccharides (GOS) (Torres et al., 2010), lactulose (Silvério et al., 2016) and lactosucrose (Li et al., 2009). These prebiotics are enzymatically obtained through the hydrolysis of lactose followed by the transfer of the galactosyl residue to a suitable acceptor, namely fructose for the disaccharide lactulose; sucrose for the trisaccharide lactosucrose; and lactose for GOS (degree of polymerization from 2 up to 8). The concept of prebiotic was introduced about twenty years ago to define a class of compounds with ability to promote specific changes in the gastrointestinal microflora with benefits upon host well-being and health. The evidence that several beneficial microorganisms at extra-gastrointestinal sites can directly or indirectly be affected by prebiotics stressed the need for an updated concept. Therefore, prebiotic is nowadays considered "a substrate that is selectively utilized by host microorganisms conferring a health benefit" (Gibson et al., 2017). Currently, only few compounds are well-accepted as prebiotics by the scientific community. This restrict group includes fructo-oligosaccharides (FOS), inulin, GOS and lactulose (Gibson et al., 2010; 2017). Besides these compounds, several other non-digestible oligosaccharides have claimed the status of prebiotics, namely lactosucrose, xylo-oligosaccharides (Seesuriyachan et al., 2017), gluco-oligosaccharides (Sharma et al., 2016), pectic oligosaccharides (Babbar et al., 2016) or isomalto-oligosaccharides (Goffin et al., 2011). Prebiotics have gained nutraceutical and pharmaceutical relevance due to their recognized contribute to maintain and restore gastrointestinal microflora, to prevent colitis and constipation, to reduce the incidence of colon cancer, to promote positive modulation of the immune system or to decrease cholesterol and obesity risk (Patel and Goyal, 2012). The prebiotic market size surpassed USD 3 billion in 2015 and it is expected to reach USD 7.5 billion by 2023 (Global Market Insights, Inc., 2017). To keep up with the growing market trend, efficient production processes ought to be developed, implemented and optimized. The enzymatic synthesis is one of the strategies used at the industrial level for the production of some prebiotics. However, the success of this methodology is in part dependent on the use of effective biocatalysts. In the synthesis of lactose-based prebiotics, such as GOS or lactulose, different microbial sources of $\beta$-galactosidase can be used (Torres et al., 2010; Silvério et al., 2016). The search for new and effective biocatalysts represents not only a potential improvement in the production process, but also an opportunity to synthesize novel compounds with enhanced or differentiated biological activity.

In this work, a screening was performed to identify new fungal sources of $\beta$-galactosidase with potential for prebiotic synthesis. The most promising microorganisms were validated as effective $\beta$-galactosidase producers under submerged fermentation conditions using lactose as carbon source. Finally, the capacity of the crude enzymatic extracts to catalyze the synthesis of several prebiotics was investigated.

\section{Materials and methods}

\subsection{Chemicals}

5-Bromo-4-chloro-3-indolyl- $\beta$-D-galactopyranoside (X-gal), O-nitrophenyl- $\beta$-D-galactopyranoside (ONPG), lactulose and lactosucrose were purchased from Sigma Aldrich (St. Louis, USA). FOS standards (1kestose (GF2), 1-nystose (GF3) and $1^{\mathrm{F}}$-fructofuranosylnystose (GF4)) were provided by Wako Pure Chemical Industries, Ltd (Osaka, Japan). A GOS mixture $(97 \% \mathrm{w} / \mathrm{w})$ containing $47 \%$ trisaccharides, $42 \%$ tetrasaccharides and $8 \%$ pentasaccharides was used as GOS standard (Torres et al., 2011). Bradford dye reagent and BSA Standard Ampoules (2 mg/ $\mathrm{mL}$ ) in a solution of $0.9 \%$ saline and $0.05 \%$ sodium azide) were purchased from Alfa Aesar (Karlsruhe, Germany) and Thermo Fisher Scientific (Waltham, USA), respectively. 


\subsection{Fungal strain}

The 50 fungal strains used in the screening test with X-gal were obtained from the collection of cultures of MUM (Micoteca of University of Minho, Portugal) and DIA-UAC (Food Research Department, Autonomous University of Coahuila, Mexico). The strains were divided into three groups: Group 1, containing 24 Aspergillus spp.; Group 2, composed by 12 Penicillium spp.; and Group 3 which includes 14 fungi from different genera (Table 1). The microorganisms were grown at $25^{\circ} \mathrm{C}$ for 7-10 days on Petri plates containing PDA (potato dextrose agar (\% w/v): potato extract (0.4), glucose (2) and agar (1.5)) or MEA (malt extract agar (\% w/v): malt extract (2), glucose (2), peptone (0.1) and agar (2)). The fungal strains evaluated for $\beta$-galactosidase production under submerged fermentation conditions were: Aspergillus ibericus (MUM 03.49), Aspergillus brasiliensis (MUM 06.179), Aspergillus restrictus (MUM 9824); Aspergillus transmontanensis (MUM 10.221); Aspergillus uvarum (MUM 08.01), Penicillium brevicompactum (MUM 02.07); Penicillium italicum (MUM 02.25); Penicillium spinulosum (MUM 02.34); Byssochlamys fulva (MUM 9827); Mucor sp. (DIA-UAC 3P); Paecilomyces variotii (MUM 9737) and Trametes versicolor (MUM 04.100).

\subsection{Chromogenic test}

The chromogenic test was performed in Petri plates containing (\% $\mathrm{w} / \mathrm{v}$ ): malt extract (2), lactose (2), peptone (0.1) and agar (2). The sterilized medium was supplemented with $0.5 \%(\mathrm{v} / \mathrm{v})$ of X-gal solution $(20 \mathrm{mg} / \mathrm{mL}$ in dimethyl sulfoxide). After inoculation, the plates were incubated and protected from light at $25^{\circ} \mathrm{C}$ for 7 days. Duplicates were prepared for all the fungi tested. The appearance of blue color in the plates was considered an indication of $\beta$-galactosidase production (Manafi, 1996). Four levels of response were defined for the chromogenic test, namely (0) no blue color; (1) slight blue color; (2) blue color; and (3) deep blue color.

\subsection{4. $\beta$-Galactosidase production}

Spore suspensions for inoculums were prepared in sterile saline solution $0.85 \%(\mathrm{w} / \mathrm{v}) \mathrm{NaCl}$ containing $0.01 \%(\mathrm{w} / \mathrm{v})$ Tween 80 . The conidia density was adjusted to $10^{6}$ conidia/mL. Fermentation medium was composed of ( $\% \mathrm{w} / \mathrm{v})$ : lactose (2), peptone (0.4), yeast extract $(0.4)$ and salts $\left(\mathrm{KH}_{2} \mathrm{PO}_{4}(0.2), \mathrm{Na}_{2} \mathrm{HPO}_{4} \cdot 12 \mathrm{H}_{2} \mathrm{O}(0.8)\right.$ and $\mathrm{MgSO}_{4} \cdot 7 \mathrm{H}_{2} \mathrm{O}$ (0.025) (Nagy et al., 2001). All the fermentations were performed in triplicate during 20 days, at $150 \mathrm{rpm}$ and $28^{\circ} \mathrm{C}$ or $37^{\circ} \mathrm{C}$, depending on the microorganism.

\section{5. $\beta$-Galactosidase activity assay}

$\beta$-Galactosidase activity was determined by incubating samples $(50 \mu \mathrm{L})$, at $37^{\circ} \mathrm{C}$ for $30 \mathrm{~min}$, with $50 \mu \mathrm{L}$ of ONPG solution $(3 \mathrm{mM})$ pre-

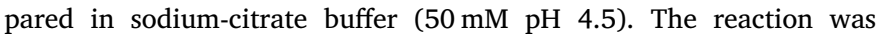
stopped by the addition of $200 \mu \mathrm{L}$ of sodium carbonate $(0.1 \mathrm{M}$ ) (Nagy et al., 2001). The released $O$-nitrophenol was determined spectrophotometrically at $415 \mathrm{~nm}$. One unit (U) of enzyme was defined as the amount of enzyme that liberates $1 \mu \mathrm{mol}$ of $O$-nitrophenol from ONPG per minute under the assay conditions.

\subsection{Biomass wet weight determination}

The fermentation broth was filtered and the biomass was conveniently washed with distilled water. In order to remove water excess, the biomass previously filtered was transferred to a Petri plate containing a double paper filter and it was allowed to air dry for 15-20 min at room temperature (Cardoso et al., 2017). Afterwards, the biomass wet weight was determined.

\subsection{Protein determination}

Protein concentration was determined using the Bradford method. The calibration curve was obtained using stock solutions of bovine serum albumin (BSA) in the concentration range from 1 to $100 \mu \mathrm{g} / \mathrm{mL}$.

\subsection{Sugars quantification}

Sugars were quantified by HPLC analysis using a Jasco chromatograph equipped with evaporative light scattering detector (Sedex85, Sedere) and a Prevail Carbohydrate ES column $(5 \mu \mathrm{m}, 250 \times 4.6 \mathrm{~mm}$, Alltech) fitted with a pre-column using the same stationary phase. A mixture of acetonitrile:water (75:25 or 70:30, v/v, depending on the sample) pumped at $0.9 \mathrm{~mL} / \mathrm{min}$ was used as mobile phase. The injection volume was defined as $20 \mu \mathrm{L}$. A calibration curve was previously prepared with standards of lactose, lactulose, lactosucrose, GOS and fructooligosaccharides (FOS) in the range $0.1-20 \mathrm{~g} / \mathrm{L}$.

\subsection{Characterization of the crude enzyme}

The fermentation broth was filtered $(0.2 \mu \mathrm{m}$ membrane) and used for further crude enzyme characterization. The effect of temperature in the enzyme activity was evaluated by determining the $\beta$-galactosidase activity in $50 \mathrm{mM}$ sodium-citrate buffer $(\mathrm{pH} 4.5)$ at different temperatures ranging from 5 to $70^{\circ} \mathrm{C}$ using the conditions previously described (section 2.5). The effect of $\mathrm{pH}$ on the enzyme activity was evaluated at $37^{\circ} \mathrm{C}$ using buffers with different $\mathrm{pH}$ ranging from 2.5 to 7.5 . The following buffers were used: $50 \mathrm{mM}$ sodium-citrate buffer ( $\mathrm{pH} 2.5-5.5)$ and $50 \mathrm{mM}$ phosphate-citrate buffer ( $\mathrm{pH} 6.5$ and 7.5). For each $\mathrm{pH}$, the enzymatic activity was determined using the conditions previously described (section 2.5). These studies were performed in triplicate.

\subsection{Prebiotic production}

The prebiotic production was investigated using the crude extract enzyme obtained after a 20 -day fermentation, at $28^{\circ} \mathrm{C}$ and $150 \mathrm{rpm}$. First, the biomass was removed by filtration $(0.2 \mu \mathrm{m}$ membrane) and the fermentation broth with $\beta$-galactosidase activity was used to study the prebiotic production. The enzymatic synthesis was performed at $37^{\circ} \mathrm{C}$ for $30 \mathrm{~h}$ by mixing $5 \mathrm{~mL}$ of the enzyme crude extract with $5 \mathrm{~mL}$ of a sugar solution $(200 \mathrm{~g} / \mathrm{L}$ lactose $+200 \mathrm{~g} / \mathrm{L}$ fructose for lactulose and GOS production, and $200 \mathrm{~g} / \mathrm{L}$ lactose $+200 \mathrm{~g} / \mathrm{L}$ sucrose for lactosucrose and GOS production) prepared in sodium-citrate buffer $(50 \mathrm{mM}$, pH 4.5) (Cardoso et al., 2017). Samples were taken at different time points $(1,3,5,10,20,25$ and $30 \mathrm{~h})$ and were further analyzed by HPLC. All enzymatic synthesis were performed in duplicate.

The substrate conversion and the prebiotic yield were calculated using the following equations, where $\mathrm{Ci}$ and $\mathrm{Cf}(\mathrm{g} / \mathrm{L})$ are the initial and final concentrations of the substrate (lactose or sucrose), respectively, and $\mathrm{Cp}$ is the concentration of prebiotics (lactulose, GOS or FOS).

Substrate conversion $=\frac{C i-C f}{C i} \times 100$

Prebiotic yield $=\frac{C p}{C i} \times 100$

\subsection{1. $\beta$-Fructofuranosidase activity assay}

$\beta$-Fructofuranosidase (FFase) activity was determined by measuring the amount of glucose released from sucrose after $20 \mathrm{~min}$ incubation at $30{ }^{\circ} \mathrm{C}$ and pH 5.0 (Yoshikawa et al., 2006). Glucose concentration was obtained by HPLC, using the same conditions described above for sugar quantification. One $\mathrm{U}$ of the FFase activity was defined as the amount of enzyme that releases $1 \mu \mathrm{mol}$ of glucose per minute from sucrose. 

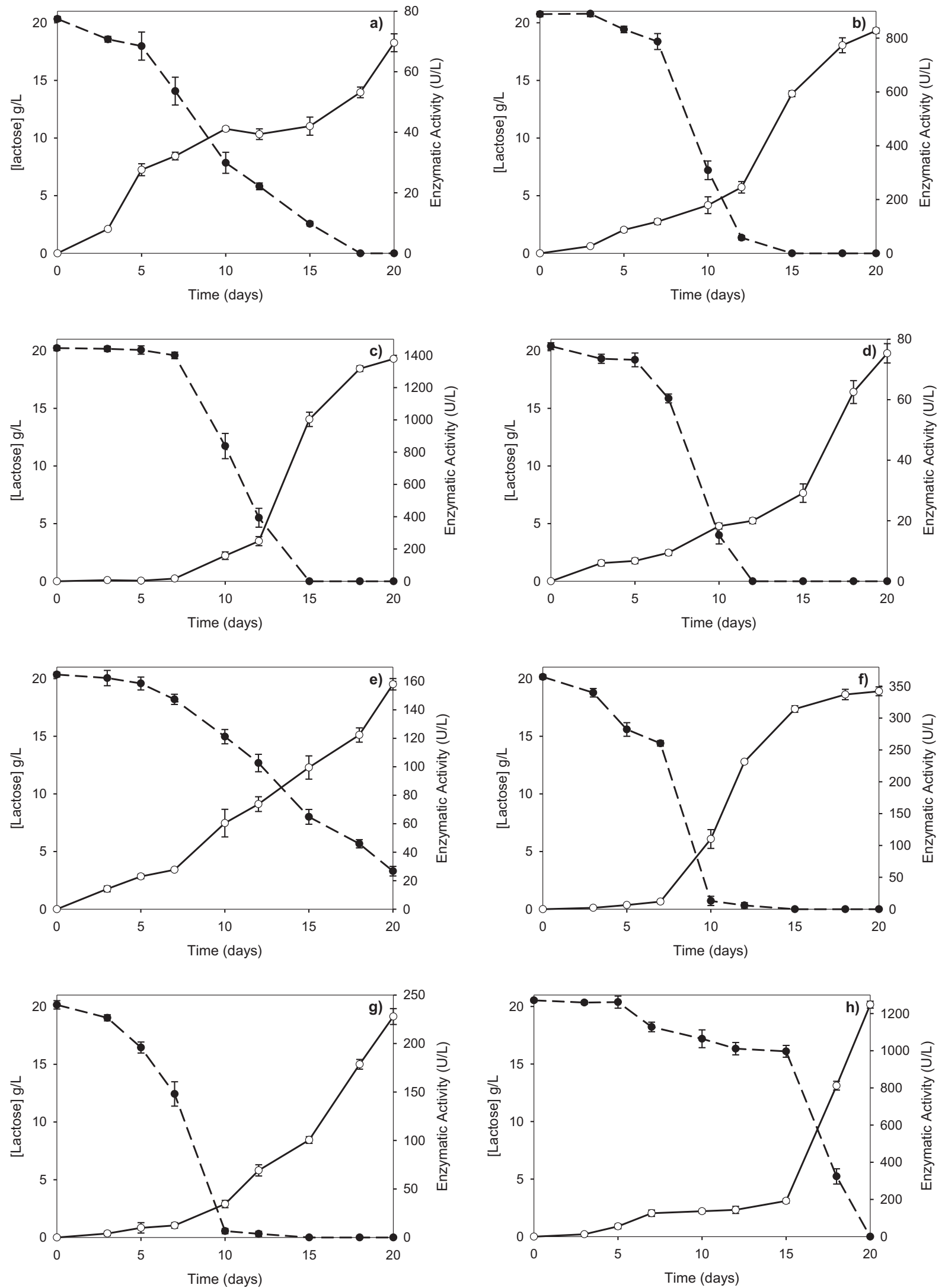

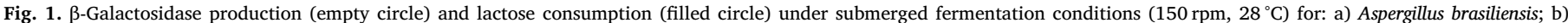

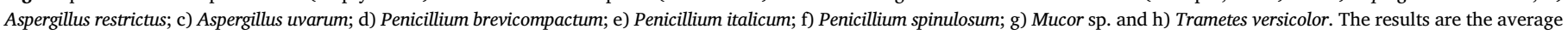
of three independent assays \pm standard deviation. 


\section{Results and discussion}

\subsection{Chromogenic test}

The results obtained for the chromogenic test performed with 50 fungal strains are presented in Table 1 , according to the levels of response previously established (section 2.3). Among the 50 microorganisms tested, a total of 42 fungi were identified as potential $\beta$-galactosidase producers. In Group 1 (Table 1), 19 Aspergillus spp. showed potential to produce $\beta$-galactosidase and only 5 strains provided a negative response to the chromogenic test. However, the levels of positive response were different among the potential enzyme producers. For $A$. carbonarius, A. ibericus, A. niger and A. restrictus a deep blue color (level 3 ) was observed on the bottom of the agar plates and the levels 2 and 1 were obtained for 9 and 6 Aspergillus spp., respectively. Among the 12 Penicillium spp. studied in Group 2 (Table 1), only P. paxilli provided a negative response to the chromogenic test. $P$. brevicompactum, $P$. italicum, $P$. purpurogenum and $P$. spinulosum presented the highest level of response, while $P$. aurantiogriseum, $P$. chrysogenum and $P$. verrucosum presented a level 2 response. A slight blue color (level 1) was observed for 4 Penicillium spp. In Group 3 (Table 1), which comprises 14 fungi from different genera, a negative response to the chromogenic test was observed for Alternaria sp. and Fusarium culmorum. For the 12 fungi identified as potential $\beta$-galactosidase producers, B. fulva, Mucor sp., $N$. crassa and $P$. variotti provided a deep blue color (level 3). The level 2 response was observed for 5 fungi, and 3 of them presented only a slight blue color (level 1).

The chromogenic test with X-gal proved to be a simple and fast approach to evaluate the potential of the 50 fungi for the production of $\beta$-galactosidase. However, this test only provides a qualitative assessment and additional studies are needed to confirm the effective production of the enzyme by the fungal strains. According to the results (Table 1), the 12 fungi exhibiting level 3 response were classified as the most promising $\beta$-galactosidase producers. Nevertheless, within this level of response, we identified A. carbonarius, A. niger and Neurospora crassa which have already been reported as producers of extracellular and/or intracellular $\beta$-galactosidase (> 200 U/L) (El-Gindy, 2003; O'Connell and Walsh, 2008; Comp and Lester, 1971; Tonelotto et al., 2014). Under submerged fermentation conditions and using culture media containing different sugars (lactose, sucrose or arabinose) and also agro-industrial residues (cheese whey or wheat bran), these fungi were able to produce $\beta$-galactosidases with catalytic activity towards different substrates such as ONPG, $p$-nitrophenyl- $\beta$-D-galactopyranoside or lactose. Therefore, and considering that our main aim is to identify novel $\beta$-galactosidase producers, these three fungi will not be included in the following studies. Also, $P$. purpurogenum, a well-known producer of a red pigment (Mendez et al., 2011) was identified in this group. The presence of the pigment could compromise the absorbance measurements in the $\beta$-galactosidase activity assay (Mapari et al., 2006) and it also represents an additional contaminant to consider in a possible purification process, thus likewise this fungus was not further used in our work. All the other fungi from level 3 (A. ibericus, A. restictus, $P$. brevicompactum, $P$. italicum, $P$. spinulosum, $B$. fulva, Mucor sp. and $P$. variotii) were evaluated as $\beta$-galactosidase producers under submerged fermentation conditions. Additionally, 4 fungi from level 2, namely $A$. brasiliensis, A. transmontanensis, A. uvarum and T. versicolor were included in the validation study since, as far as we know, their ability to produce $\beta$-galactosidase has never been studied.

\section{2. $\beta$-Galactosidase production}

From the submerged fermentations performed for 20 days in a synthetic medium containing lactose it was demonstrated that $B$. fulva and $P$. variotti were not able to produce $\beta$-galactosidase, while $A$. ibericus and $A$. transmontanensis presented very low levels of enzymatic activity in the fermentation broth (approximately 28 and $25 \mathrm{U} / \mathrm{L}$, 
respectively). These results suggest that changes in type of fermentation, medium composition and temperature may have a negative impact in the $\beta$-galactosidase production. Similarly, the use of a different enzymatic assay with a different chromogenic substrate may also affect the detection of $\beta$-galactosidase activity (Manafi, 1996). For all the other fungi, the profiles obtained for the lactose consumption and $\beta$ galactosidase production are presented in Fig. 1. It was observed that the hydrolysis and consumption of lactose is generally associated with an increase of the extracellular enzymatic activity. All the lactose from the culture medium was exhausted during the fermentation, except for $P$. italicum for which approximately $3 \mathrm{~g} / \mathrm{L}$ of sugar remained in the fermentation broth after 20 days. Among all the studied fungi, some were better $\beta$-galactosidase producers than others according to the following order: A. uvarum $(1377 \mathrm{U} / \mathrm{L})>T$. versicolor $(1248 \mathrm{U} /$ L) $>$ A. restrictus $(828 \mathrm{U} / \mathrm{L})>P$. spinulosum $(324 \mathrm{U} / \mathrm{L})>$ Mucor sp. $(228 \mathrm{U} / \mathrm{L})>$ P. italicum $(158 \mathrm{U} / \mathrm{L})>P$. brevicompactum $(75 \mathrm{U} / \mathrm{L}) \approx A$. brasiliensis $(70 \mathrm{U} / \mathrm{L})$. The specific activity $(\mathrm{U} / \mathrm{mg})$ at the end of the fermentation was also determined and it is presented in Table 2, together with the final biomass obtained for each fungus. In all cases, no correlation was found between the biomass and $\beta$-galactosidase production. The highest specific activities were found for T. versicolor and A. uvarum. On the other hand, $P$. brevicompactum showed the lowest specific activity value.

\section{3. $\beta$-Galactosidase characterization}

The crude extract obtained after filtration of the fermentation broth was used in the enzyme characterization. The results obtained for the effect of temperature and $\mathrm{pH}$ on the enzymatic activity (hydrolytic activity using ONPG as substrate) are shown in Fig. 2 and the optimal values found for each enzyme are described in Table 2. All the fungal $\beta$ galactosidases presented optimal $\mathrm{pH}$ in the acidic range between 3.0 and 5.5. In general, the enzymatic activity decreased significantly for higher $\mathrm{pH}$ values, except for $A$. brasiliensis and $P$. brevicompactum. Regarding $A$. brasiliensis, two ranges of optimal $\mathrm{pH}$ were found, namely $3.0-5.0$ and 6.5-7.0. This result can possibly be explained by the presence of isoenzymes in the crude extract. $P$. brevicompactum showed an optimal $\mathrm{pH}$ in the range $4.5-5.5$, nevertheless, its enzymatic activity remained considerable high $(>75 \%$ ) for $\mathrm{pH}$ values between 2.5 and 7.0.

The optimal temperature for all fungi was obtained between $45^{\circ} \mathrm{C}$ and $65^{\circ} \mathrm{C}$ (Table 2). Generally, the enzymes presented a range of temperatures in which they remain active. However, for $P$. brevicompactum and $P$. italicum the maximal enzymatic activity was observed for a single temperature $\left(55^{\circ} \mathrm{C}\right)$.

The results herein gathered for optimal temperature and $\mathrm{pH}$ are similar to those reported in the literature for other $\beta$-galactosidases from Aspergillus spp. (Gargova et al., 1995; Gonzalez and Monsan, 1991; O'Connell and Walsh, 2008; Tonelotto et al., 2014; Roal et al., 2015), Penicillium spp. (Watanabe et al., 1979; Cruz et al., 1999; Nagy et al., 2001) and Mucor spp. (Ismail et al., 1997; Shaikh 1999). Generally, fungal $\beta$-galactosidases present optimal $\mathrm{pH}$ in the acidic range and have relatively high optimal temperature (O'Connell and Walsh, 2008). The optimal conditions obtained for the commercial substrate ONPG, namely the acidic $\mathrm{pH}$, suggest, for instance, the suitability of these enzymes to catalyze lactose hydrolysis in acid cheese whey (Rosolen et al., 2015). Furthermore, these 8 fungal enzymes seem to have potential for the prebiotic synthesis under the reaction conditions generally reported for other fungal $\beta$-galactosidases (Torres et al., 2010; Silvério et al., 2016).

\subsection{Prebiotic synthesis}

To investigate the ability of $\beta$-galactosidases to catalyze both the hydrolytic and transfer reactions involved in the production of lactosebased prebiotics, different substrate mixtures were used (Cardoso et al.,
2017). The results obtained for each fungal $\beta$-galactosidase are summarized in Table 2. When the crude enzymes were incubated with a mixture of lactose + fructose, two types of prebiotic were formed, namely lactulose and GOS. A. restrictus and A. uvarum provided the highest lactulose concentration ( 3.3 and $3.2 \mathrm{~g} / \mathrm{L}$, respectively), while the lowest values of lactulose concentration were obtained by $A$. brasiliensis and Mucor sp. The GOS concentration presented in Table 2 corresponds mainly to a trisaccharide which probably has the same structure for all the $\beta$-galactosidases studied (as suggested by the similar retention time in all the chromatograms using a well-characterized GOS mixture as standard (Torres et al., 2011)). For A. restrictus and A. uvarum traces of a tetrasaccharide were also detected. This observation is in good agreement with the results presented in Table 2 since the highest concentrations of trisaccharide GOS, the precursor of the tetrasaccharide, were found for these two fungi. Generally, the synthesis of GOS and lactulose was detected $3 \mathrm{~h}$ after incubation. However, for A. brasiliensis, P. spinulosum and T. versicolor the production of lactulose was only observed after $5 \mathrm{~h}$. The maximal lactulose and GOS concentration was reached after $25-30 \mathrm{~h}$ of reaction for almost all of the fungi, except for A. brasiliensis, Mucor sp. and T. versicolor. For these three fungi, the maximal prebiotic concentration was detected at $20 \mathrm{~h}$ of incubation and a decrease was observed afterwards, probably due to some product degradation i.e. secondary hydrolysis of GOS and lactulose (Osman et al., 2014; Sitanggang et al., 2014; Guerrero et al., 2017). On the other hand, the lactose conversion (\%) increased overtime for all the $\beta$-galactosidases studied and the highest percentages of conversion are generally associated with the highest prebiotic concentrations (Table 2).

When the crude enzymes were incubated with a mixture of lactose + sucrose, the only lactose-based prebiotic detected was the trisaccharide GOS (similar retention time in all chromatograms) (Table 2). The maximal GOS concentration was reached after $25-30 \mathrm{~h}$ of reaction, being the highest values obtained for $A$. restrictus $(20 \pm 0.3 \mathrm{~g} / \mathrm{L}), A$. uvarum $(15 \pm 0.4 \mathrm{~g} / \mathrm{L})$ and $T$. versicolor $(8.6 \pm 0.3 \mathrm{~g} / \mathrm{L})$. Similarly, the highest percentages of lactose conversion after $30 \mathrm{~h}$ of reaction were also detected for these three microorganisms (Table 2). The production of lactosucrose was not observed for any studied fungus. Cardoso et al. (2017) also reported the absence of lactosucrose production by $\beta$-galactosidase from Aspergillus lacticoffeatus under similar reaction conditions. A possible explanation for this fact is the apparent inability of fungal $\beta$-galactosidases to catalyze the production of this prebiotic (Cardoso et al., 2017). The enzymatic production of lactosucrose using $\beta$-galactosidase as biocatalyst is poorly studied and the few references found in the literature only report the successful use of bacterial $\beta$ galactosidase produced by Bacillus circulans (Farkas et al., 2003; Li et al., 2009; Duarte et al., 2017). On the other hand, it is important to highlight that lactosucrose production was herein evaluated under unoptimized conditions. It is well-known that reaction parameters such as substrate concentration, substrate molar ratio, enzyme concentration, temperature or reaction time, can significantly affect the amount of lactosucrose and the composition of the final product (Farkas et al., 2003; Li et al., 2009; Duarte et al., 2017). Therefore, different reaction conditions should be carefully studied in the future prior to unequivocally conclude about the inability of fungal $\beta$-galactosidase to synthesize this prebiotic.

Although no lactosucrose was produced during the reaction times evaluated, the conversion of sucrose was observed for all the fungal $\beta$ galactosidases, except for $A$. restrictus and Mucor sp. In general, the conversion was firstly detected at $3-5 \mathrm{~h}$ of reaction, but for $A$. brasiliensis and T. versicolor it started after $1 \mathrm{~h}$. This observation suggested the presence of FFase activity in the crude extracts. For that reason, an enzymatic assay was performed to determine this catalytic activity (section 2.11). The results obtained are presented in Table 2. As expected, FFase activity was detected in the enzymatic extracts which previously showed sucrose conversion. Furthermore, the highest percentage of sucrose conversion corresponded to the crude extracts with 

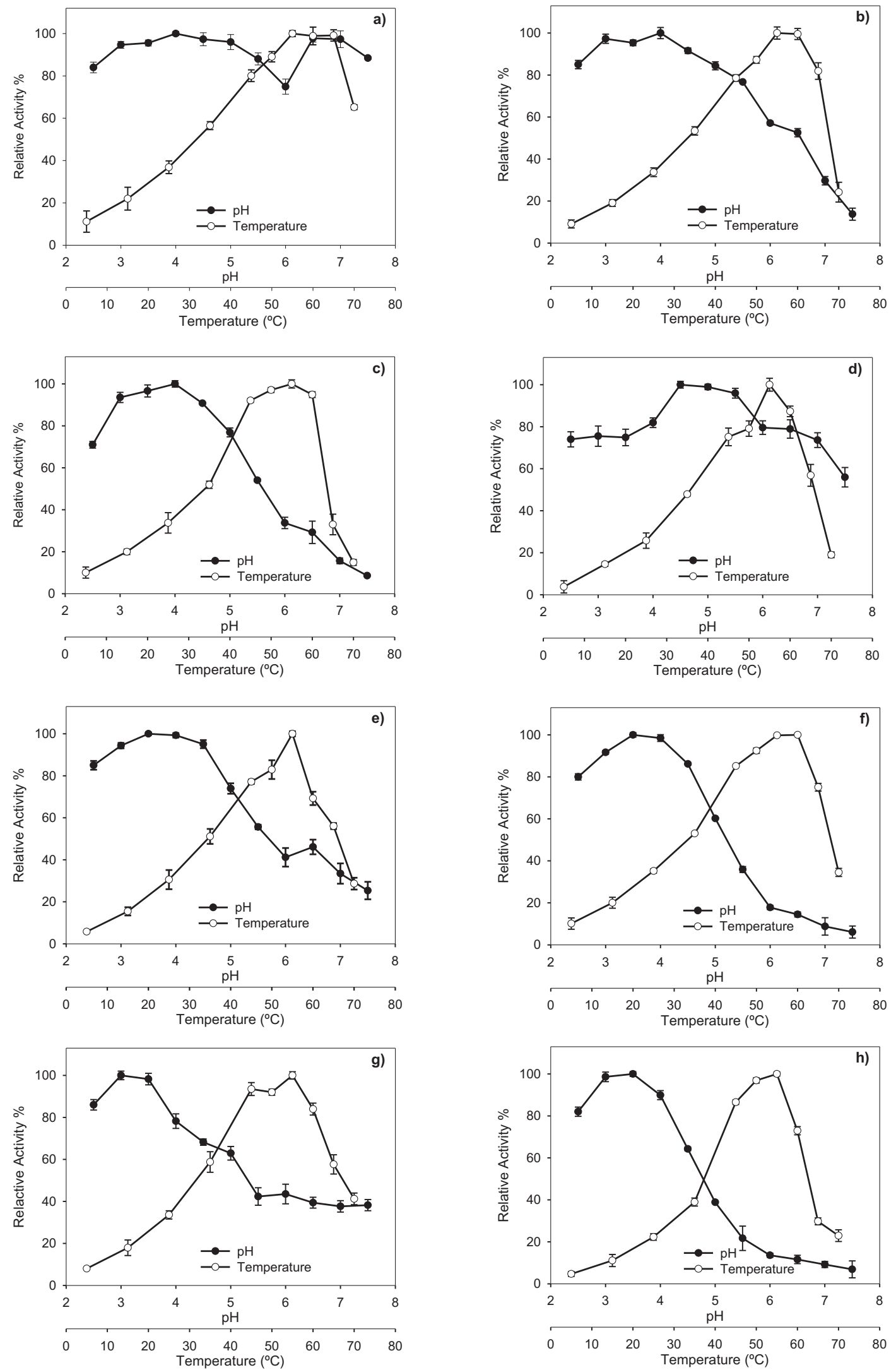

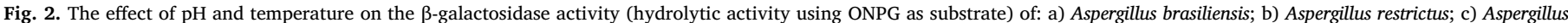

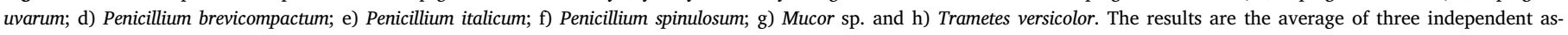
says \pm standard deviation. 
highest FFase activity. The HPLC analysis revealed that sucrose present in the sugar mixtures was not exclusively hydrolyzed into fructose and glucose, it was also used in transfructosylation reactions to produce FOS (Table 2). A similar result was reported by Cardoso et al. (2017) for enzymatic extracts from A. lacticoffeatus containing both $\beta$-galactosidase and FFase activity.

In general, the enzymatic synthesis of FOS (GF2) was observed after $3-5 \mathrm{~h}$ of reaction and their concentration increased during the reaction time. Nevertheless, for $A$. brasiliensis the maximal concentration $(5.1 \pm 0.2 \mathrm{~g} / \mathrm{L})$ was reached at $10 \mathrm{~h}$, followed by a progressive reduction to $3.6 \pm 0.3 \mathrm{~g} / \mathrm{L}(30 \mathrm{~h})$ probably due to some product degradation (L'Homme et al., 2003), since no longer structures of FOS were detected by HPLC. In almost all cases, the FOS concentration presented in Table 2 corresponds to a GF2 structure (retention time similar to the standard 1-kestose in all chromatograms). The only exception occurred with the enzymatic extract from $P$. brevicompactum which allowed the synthesis of three different structures of FOS (GF2, GF3 and GF4). After $30 \mathrm{~h}$ of reaction, three FOS are detected, together with a GOS structure (trisaccharide). The presence of fructose, glucose and galactose in the mixture was also observed, indicating that considerable amount of both substrates (lactose and sucrose) suffered enzymatic hydrolysis. Fig. 3 illustrates the profile of GOS and FOS production using the crude enzymatic extract from $P$. brevicompactum. The simultaneous synthesis of GF2 and GOS was detected after $1 \mathrm{~h}$ $(2.7 \pm 0.4$ and $0.93 \pm 0.13 \mathrm{~g} / \mathrm{L}$, respectively), while the synthesis of GF3 $(3.2 \pm 0.4 \mathrm{~g} / \mathrm{L})$ and GF4 $(3.3 \pm 0.3 \mathrm{~g} / \mathrm{L})$ was only detected after 3 and $5 \mathrm{~h}$ of reaction, respectively. Both GOS and total FOS concentration increased over time. However, after $20 \mathrm{~h}$, the concentration of GF2 $(14.2 \pm 0.6 \mathrm{~g} / \mathrm{L})$ was reduced and the concentrations of GF3 and GF4 were slowly raised. The total FOS concentration obtained at $30 \mathrm{~h}$ (approximately $30 \mathrm{~g} / \mathrm{L}$ ) corresponds to $12.4 \pm 0.6 \mathrm{~g} / \mathrm{L}$ of GF2, $11.8 \pm 0.4 \mathrm{~g} / \mathrm{L}$ of GF3 and $5.5 \pm 0.3 \mathrm{~g} / \mathrm{L}$ of GF4. These values represent a FOS yield of around 30\% (grams of total FOS per grams of initial sucrose), which is higher than some yields reported in the literature for crude enzymes under optimized conditions. Muñiz-Márquez et al. (2016) obtained around $25 \%$ yield using aguamiel, a by-product obtained from maguey, as sucrose source and fructosyltransferase from Aspergillus oryzae. A yield of $16 \%$ was achieved by Silva et al. (2014) using levansucrase from Bacillus subtilis. However, the FOS yield here obtained is far from the maximal theoretical yield (55-60\%) generally associated with a two-step process (enzyme production + crude enzyme application) (Sangeetha et al., 2005). The FOS yield is limited by the high amounts of glucose generated during sucrose hydrolysis which will act as enzyme inhibitor. For that reason, several strategies have

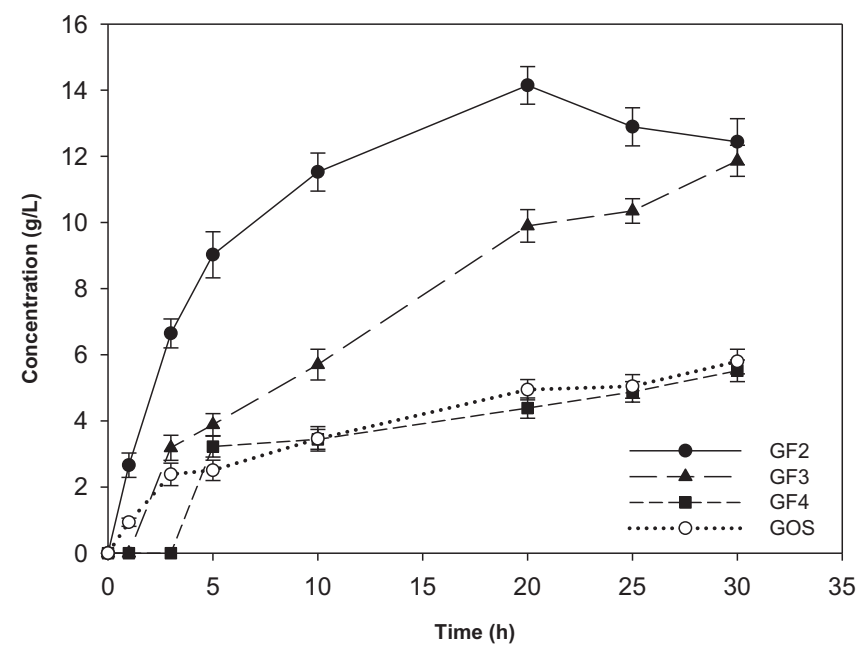

Fig. 3. GOS and FOS production using crude enzymatic extract from Penicillium brevicompactum. Enzymatic reaction performed using lactose $(100 \mathrm{~g} / \mathrm{L})$ and sucrose $(100 \mathrm{~g} / \mathrm{L})$ as substrates at $37^{\circ} \mathrm{C}$ and $\mathrm{pH} 4.5$. been proposed to remove glucose from the reaction medium and increase the yield (Dominguez et al., 2014; Nobre et al., 2016). Glucose inhibition probably exerted a crucial impact in the FOS synthesis under the reaction conditions used in the present work, since the enzymatic hydrolysis of both substrates originated glucose as a reaction product.

The different enzyme concentrations (U/L) used in this study, do not allow a direct comparison of the potential of the several fungi under study for the synthesis of prebiotics. Nevertheless, this simple approach clearly demonstrated the ability of these fungal sources of $\beta$-galactosidase to produce lactulose and GOS, and FFase to synthesize FOS. However, it is important to stress the need of additional studies using optimized conditions and/or purified enzymes to better evaluate the potential of each biocatalyst.

The occurrence of hydrolysis and transglycosylation of both lactose and sucrose is a clear evidence of the lack of purity of the obtained crude extracts (Lindamood et al., 1989). Nevertheless, this fact also points out the potential of these enzymatic extracts to simultaneously synthetize two different types of prebiotics, namely lactose-based and sucrose-based oligosaccharides. As far as we know, this strategy of prebiotic production was never explored and could represent an interesting approach to obtain prebiotic mixtures with enhanced biological effect. Actually, the intake of GOS and FOS mixtures can present advantages over the consumption of the individual prebiotics due to the occurrence of possible synergistic effects (Moro et al., 2002). Combinations of GOS and FOS have been described to improve intestinal health (Boehm et al., 2002), to reduce allergic reactions and atopic dermatitis (Vandenplas et al., 2014), to increase bone mineralization (Bryk et al., 2015) or to treat stress-related disorders (Burokas et al., 2017). The optimization of the simultaneous production of FOS and GOS, together with the implementation of strategies for the removal of monosaccharides or unreacted sugars, could significantly contribute to increase the prebiotic yields and should be further investigated. Additionally, the possibility to obtain mixtures of GOS and FOS with different concentrations and compositions offers the opportunity to explore new biological applications for prebiotics.

\section{Conclusions}

Eight fungal strains were validated as effective $\beta$-galactosidase producers. The enzymes presented optimal $\mathrm{pH}$ in the acidic range (3.0-5.5) and optimal temperature between 45 and $65{ }^{\circ} \mathrm{C}$. All the $\beta$ galactosidases showed potential for the synthesis of GOS and lactulose. Furthermore, some crude extracts exhibiting FFase activity allowed the production of FOS. Therefore, a novel and interesting approach for the simultaneous synthesis of GOS and FOS was proposed based on the application of enzymatic extracts with dual catalytic activity. The diversity of GOS and FOS mixtures originated with this strategy can contribute to obtain new and/or improved prebiotic effects.

\section{Acknowledgements}

This study was supported by the Portuguese Foundation for Science and Technology (FCT) under the scope of the strategic funding of UID/ BIO/04469/2013 unit and COMPETE 2020 (POCI-01-0145-FEDER006684), and also by the project BioTecNorte (NORTE-01-0145-FEDER000004) and the project MultiBiorefinery (POCI-01-0145-FEDER016403) funded by the European Regional Development Fund under the scope of Norte2020 - Programa Operacional Regional do Norte. SCS acknowledges her post doc grant (SFRH/BPD/88584/2012) from FCT. EA Macedo is a member of the Associate Laboratory LSRE-LCM, Project POCI-01-0145-FEDER-006984, funded by FEDER through COMPETE2020 - Programa Operacional Competitividade e Internacionalização (POCI) - and by national funds through FCT Fundação para a Ciência e a Tecnologia. 


\section{Appendix A. Supplementary data}

Supplementary data associated with this article can be found, in the online version, at http://dx.doi.org/10.1016/j.biortech.2017.11.045.

\section{References}

Babbar, N., Dejonghe, W., Gatti, M., Sforza, S., Elst, K., 2016. Pectic oligosaccharides from agricultural by-products: production, characterization and health benefits. Crit. Rev. Biotechnol. 36, 594-606.

Bhatnagar, S., 2007. Lactose intolerance. Brit. Med. J. 334, 1331-1332.

Boehm, G., Lidestri, M., Casetta, P., Jelinek, J., Negretti, F., Stahl, B., Marini, A., 2002. Supplementation of a bovine milk formula with an oligosaccharide mixture increases counts of faecal bifidobacterial in preterm infants. Arch. Dis. Child Fetal Neonatal Ed. 86, F178-181.

Bryk, G., Coronel, M.Z., Pellegrini, G., Mandalunis, P., Rio, M.E., Portela, M.L.P.M., Zeni, S.N., 2015. Effect of a combination GOS/FOS ${ }^{\circledast}$ prebiotic mixture and interaction with calcium intake on mineral adsorption and bone parameters in growing rats. Eur. J. Nutr. 54, 913-923.

Burokas, A., Arboleya, S., Moloney, R.D., Peterson, V.L., Murphy, K., Clarke, G., Stanton, C., Dinan, T.G., Cryan, J.F., 2017. Targeting the microbiota-gut-brain axis: prebiotics have anxiolytic and antidepressant-like effects and reverse the impact of chronic stress in mice. Biol. Psychiat. 82, 472-487.

Cardoso, B.B., Silvério, S.C., Abrunhosa, L., Teixeira, J.A., Rodrigues, L.R., 2017. ßGalactosidase from Aspergillus lacticoffeatus: a promising biocatalyst for the synthesis of novel prebiotics. Int. J. Food Microbiol. 257, 67-74.

Comp, P.C., Lester, G., 1971. Properties of an extracellular $\beta$-galactosidase secreted by Neurospora crassa. J. Bacteriol. 107, 162-167.

Cruz, R., Cruz, V.D'.A., Belote, J.G., Khenayfes, M.O., Dorta, C., Oliveira, L.H.S., 1999. Properties of a new fungal $\beta$-galactosidase with potential application in the dairy industry. Rev. Microbiol. 30, 265-271.

Dominguez, A.L., Rodrigues, L.R., Lima, N.M., Teixeira, J.A., 2014. An overview of the recent developments on fructooligosaccharide production and applications. Food Bioprocess Technol. 7, 324-337.

Duarte, L.S., Schöffer, J.N., Lorenzoni, A.S.G., Rodrigues, R.C., Rodrigues, E., Hertz, P.F., 2017. A new bioprocess for the production of prebiotic lactosucrose by an immobilized $\beta$-galactosidase. Process Biochem. 55, 96-103.

El-Gindy, A., 2003. Production, partial purification and some properties of beta-galactosidase from Aspergillus carbonarius. Folia Microbiol. 48, 581-584.

Farkas, E., Schmidt, U., Thiem, J., Kowalczyk, J., Kunz, M., Vogel, M., 2003. Regioselective synthesis of galactosylated tri- and tetra-saccharides by use of $\beta$-galactosidase from Bacillus circulans. Synthesis 5, 699-706.

Fox, P.F., McSweeney, P.L.H., 1998. Dairy Chemistry and Biochemistry. Kluwer Academic/Plenum Publishers, New York.

Gänzle, M.G., Haase, G., Jelen, P., 2008. Lactose: crystallization, hydrolysis and valueadded derivatives. Int. Dairy J. 18, 685-694.

Gargova, S., Pishtijski, I., Stoilova, I., 1995. Purification and properties of $\beta$-galactosidase from Aspergillus oryzae. Biotechnol. Biotechnol. Equip. 9, 47-51.

Gibson, G.R., Scott, K.P., Rastall, R.A., Tuohy, K.M., Hotchkiss, A., Dubert-Ferrandon, A., Gareau, M., Murphy, E.F., Saulnier, D., Loh, G., Macfarlane, S., Delzenne, N., Ringel, Y., Kozianowski, G., Dickmann, R., Lenoir-Wijnkook, I., Walker, C., Buddington, R., 2010. Dietary prebiotics: Current status and new definition. Food Sci. Technol. Bull: Funct. Foods 7, 1-19.

Gibson, G.R., Hutkins, R., Sanders, M.E., Prescott, S.L., Reimer, R.A., Salminen, S.J., Scott, K., Stanton, C., Swanson, K.S., Cani, P.D., Verbeke, K., Reid, G., 2017. Expert consensus document: the international scientific association for probiotics and prebiotics (ISAPP) consensus statement on the definition and scope of prebiotics. Nat. Rev. Gastroenterol. Hepatol. 14, 491-502.

Global Market Insights, Inc. 2017 Prebiotics Market Size. https://www.gminsights.com/ pressrelease/prebiotics-market-size.

Goffin, D., Delzenne, N., Blecker, C., Hanon, E., Deroanne, C., Paquot, M., 2011. Will isomalto-oligosaccharides, a well-established functional food in Asia, break through the European and American market? the status ok knowledge on these prebiotics. Crit. Rev. Food Sci. Nutr. 51, 394-409.

Gonzalez, R.R., Monsan, P., 1991. Purification and some characteristics of $\beta$-galactosidase from Aspergillus fonsecaeus. Enzym. Microb. Technol. 13, 349-352.

Guerrero, C., Vera, C., Illanes, A., 2017. Fed-batch operation for the synthesis of lactulose with $\beta$-galactosidase of Aspergillus oryzae. Bioresour. Technol. 237, 126-134.

Ismail, S.A., Mabrouk, S.S., Mahoney, R.R., 1997. Purification and characterization of $\beta$ galactosidase from Mucor pusillus. J. Food Biochem. 21, 145-162.

L'Homme, L'.C., Arbelot, M., Puigserver, A., Biagini, A., 2003. Kinetics of hydrolysis of fructooligosaccharides in mineral-buffered aqueous solutions: influence of $\mathrm{pH}$ and temperature. J. Agric. Food Chem. 51, 224-228.

Li, W., Xiang, X., Tang, S., Hu, B., Tian, L., Sun, Y., Ye, H., Zeng, X., 2009. Effective enzymatic synthesis of lactosucrose and its analogues by beta-D-galactosidase from Bacillus circulans. J. Agric. Food Chem. 57, 3927-3933.
Lindamood, J.B., Grooms, D.J., Hansen, P.M.T., 1989. Effect of hydrolysis of lactose and sucrose on firmness of ice cream. Food Hydrocolloid. 3, 379-388.

Manafi, M., 1996. Fluorogenic and chromogenic enzyme substrates in culture media and identification tests. Int. J. Food Microbiol. 31, 45-58.

Mapari, S.A.S., Meyer, A.S., Thrane, U., 2006. Colorimetric characterization for comparative analysis of fungal pigments and natural food colorants. J. Agric. Food Chem. 54, 7027-7035.

Méndez, A., Pérez, C., Montañéz, J.C., Martínez, G., Aguilar, C.N., 2011. Red Pigment production by Penicillium purpurogenum $\mathrm{GH} 2$ is influenced by $\mathrm{pH}$ and temperature. $\mathrm{J}$. Zhejiang Univ.-Sci. B (Biomed. \& Biotechnol.) 12, 961-968.

Moro, G., Minoli, I., Mosca, M., Fanaro, S., Jelinek, J., Stahl, B., Boehm, G., 2002. Dosagerelated bifidogenic effects of galacto- and fructooligosaccharides in formula-fed term infants. J. Pediatr. Gastr. Nutr. 34, 291-295.

Muñiz-Márquez, D.B., Contreras, J.C., Rodríguez, R., Mussatto, S.I., Teixeira, J.A., Aguilar, C.N., 2016. Enhancement of fructosyltransferase and fructooligosaccharides production by $A$. oryzae DIA-MF in solid-state fermentation using aguamiel as culture medium. Bioresour. Technol. 213, 276-282.

Nagy, Z., Kiss, T., Szentirmai, A., Biró, S., 2001. ß-galactosidase of Penicillium chrysogenum: production, purification, and characterization of the enzyme. Protein Expres. Purif. 21, 24-29.

Nobre, C., Castro, C.C., Hantson, A.-L., Teixeira, J.A., De Weireld, G., Rodrigues, L.R., 2016. Strategies for the production of high-content fructo-oligosaccharides through the removal of small saccharides by co-culture or successive fermentation with yeast. Carbohyd. Polym. 136, 274-281.

O'Connell, S., Walsh, G., 2008. Application relevant studies of fungal $\beta$-galactosidases with potential application in the alleviation of lactose intolerance. Appl. Biochem. Biotechnol. 149, 129-138.

Osman, A., Symeou, S., Trisse, V., Watson, K.A., Tzortzis, G., Charalampopoulos, D., 2014. Synthesis of prebiotic galactooligosaccharide from lactose using bifidobacterial $\beta$-galactosidase (BbgIV) immobilized on DEAE-Cellulose, Q-Sepharose and aminoethyl agarose. Biochem. Eng. J. 82, 188-199.

Patel, S., Goyal, A., 2012. The current trends and future perspectives of prebiotics research: a review. 3 Biotech 2, 115-125.

Roal, G.G., Roal, B.V., Prajapati, V.S., Patel, K.C., 2015. Kinetic and thermodynamic characterization of a halotolerant $\beta$-galactosidase produced by halotolerant Aspergillus tubingensis. J. Basic Microbiol. 55, 879-889.

Rosolen, M.D., Gennari, A., Volpato, G., Souza, C.F.V., 2015. Lactose hydrolysis in milk and dairy whey using microbial $\beta$-galactosidases. Enzyme Res., 806240.

Sangeetha, P.T., Ramesh, M.N., Prapulla, S.G., 2005. Maximization of fructooligosaccharide production by two stage continuous process and its scale up. J. Food Eng. $68,57-64$.

Seesuriyachan, P., Kawee-ai, A., Chaiyaso, T., 2017. Green and chemical-free process of enzymatic xylooligosaccharide production from corncob: enhancement of the yields using a strategy of lignocellulosic destructuration by ultra-high pressure pretreatment. Bioresour. Technol. 241, 537-544.

Shaikh, S.A., 1999. Studies on Extracellular $\beta$-Galactosidase From Thermophilic Fungus Mucor sp. PhD Thesis. University of Pune, India.

Sharma, M., Patel, S.N., Lata, K., Singh, U., Krishania, M., Sangwan, R.S., Singh, S.P., 2016. A novel approach of integrated bioprocessing of cane molasses for production of prebiotic and functional bioproducts. Bioresour. Technol. 219, 311-318.

Silva, P.B., Borsato, D., Celligoi, M.A.P.C., 2014. High production of fructooligosaccharides by levansucrase from Bacillus subtilis natto CCT 7712. Afr. J. Biotechnol. 13, 2734-2740.

Silvério, S.C., Macedo, E.A., Teixeira, J.A., Rodrigues, L.R., 2016. Biocatalytic approaches using lactulose: end product compared with substrate. Compr. Rev. Food Sci. Food Safety $15,878-896$.

Sitanggang, A.B., Drew, A., Kraume, M., 2014. Continuous synthesis of lactulose in an enzymatic membrane reactor reduces lactulose secondary hydrolysis. Bioresour. Technol. 137, 108-115.

Tonelotto, M., Pirota, R.D.P.B., Delabona, P.S., Barros, G.O.F., Golubev, A.M., Polikarpov, I., Farinas, C.S., 2014. Isolation and characterization of a $\beta$-galactosidase from a new Amazon forest strain of Aspergillus niger as a potential accessory enzyme for biomass conversion. Biocatal. Biotransform. 32, 13-22.

Torres, D.P.M., Gonçalves, M.P.F., Teixeira, J.A., Rodrigues, L.R., 2010. Galacto-oligosaccharides: production, properties, applications, and significance as prebiotics. Compr. Rev. Food Sci. Food Safety 9, 438-454.

Torres, D.P.M., Bastos, M., Gonçalves, M.P.F., Teixeira, J.A., Rodrigues, L.R., 2011. Water sorption and plasticization of an amorphous galacto-oligosaccharide mixture. Carbohyd. Polym. 83, 831-835.

Vandenplas, Y., De Greef, E., Veereman, G., 2014. Prebiotics in infant formula. Gut Microbes 5, 681-687.

Watanabe, Y., Kibesaki, Y., Tekenishi, S., Sakai, K., Tsujisaka, Y., 1979. Purification and properties of $\beta$-galactosidase from Penicillium citrinum. Agric. Biol. Chem. 43, 943-950.

Yoshikawa, J., Amachi, S., Shinoyama, H., Fujii, T., 2006. Multiple $\beta$-fructofuranosidases by Aureobasidium pullulans DSM2404 and their roles in fructooligosaccharide production. FEMS Microbiol. Lett. 265, 159-163. 